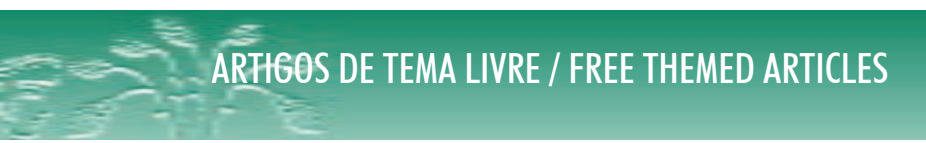

DOI: 10.12957/demetra.2015.16094

\title{
Alimentação, New Age e Saúde Holística
}

\section{Food, New Age and Holistic Health}

Virgínia Henriques Calado?

${ }^{1}$ Instituto de Ciências Sociais da Universidade de Lisboa/Centro em Rede de Investigação em Antropologia. Fundação para a Ciência e Tecnologia (FCT). Lisboa, Portugal.

Apoio financeiro: Pesquisa comparticipada por Fundos nacionais do Ministério da Educação e Ciência SFRH/BPD/97532/2013

Correspondência / Correspondence Virgínia Henriques Calado Instituto de Ciências Sociais Av. Professor Aníbal de Bettencourt, 9 1600-189 Lisboa, Portugal E-mail:vmcalado@ics.ul.pt

\section{Resumo}

Apresentando-se frequentemente como via terapêutica, a alimentação macrobiótica parte de um conjunto de princípios orientadores que salientam a interdependência de todos os fenômenos, apontando para a necessidade de compreender o corpo humano como um todo, como um microcosmos no qual o universo se reflete. Encontramos, desta forma, uma narrativa que parece remeter para esse vasto e cada vez mais globalizado fenômeno que é o New Age. Em contrapartida, é possível observar entre os partidários desse tipo de alimentação certa recusa relativa ao enquadramento da macrobiótica no fenômeno New Age. Do que se tratará aqui será, pois, de discutir, tendo em consideração dados etnográficos, o enquadramento da alimentação macrobiótica no movimento New Age de saúde holística.

Palavras-chave: Antropologia da Alimentação. Alimentação Macrobiótica. New Age. Saúde Holística.

\section{Abstract}

Often presented as therapeutic route, the macrobiotic diet departs from a set of guiding principles that emphasize the interdependence of all phenomena, pointing to the need to understand the human body as a whole, as a microcosm in which the universe is reflected. We find, therefore, a narrative that seems to refer to this vast and increasingly global phenomenon that is the New Age. On the other hand, it can be noticed among the supporters of this type of feeding certain refusal on the framework 
of macrobiotics in the New Age phenomenon. Therefore it will be discussed here, taking into account ethnographic data, the framework of the macrobiotic diet in the New Age movement of holistic health.

Key words: Anthropology of Food. Macrobiotics. New Age. Holistic Health.

\section{Alimentos a evitar e instrumentalização do conhecimento científico}

"Já imaginou se tudo o que sabe sobre o leite fosse mentira? Já alguma vez pensou que tudo o que lhe ensinaram, desde criança, acerca do leite, pode não ser verdade? Sabe que há quem defenda que o leite de vaca é uma das piores fontes de cálcio para a nossa espécie? E que 'três copos de leite por dia contra a osteoporose' pode não passar de uma falácia dos media? E, já agora, saiba também que todos os anos a indústria dos lacticinios americana gasta centenas de milhares de dólares para garantir que o povo americano continue a beber leite e a comer lacticinios. E esta é uma das principais razões pelas quais os Estados Unidos são um dos quatro paises do mundo com os mais altos níveis de osteoporose"."

Esse breve trecho foi retirado de um artigo publicado numa revista de divulgação da alimentação macrobiótica - Magna Vita - destinada a elucidar os leitores sobre os efeitos nocivos do leite. Poderia servir de mote a qualquer sessão de esclarecimento sobre alimentação macrobiótica, pois elege como tema central de debate o esclarecimento sobre os alimentos que consumimos - neste caso, o leite proveniente de outras espécies que não a humana -, mas poderia também fazer parte de uma sessão organizada por nutricionistas mais críticos acerca dos supostos benefícios do consumo de leite. O evitamento do leite, recomendação que num passado recente foi vista como destituída de fundamento, passou a figurar na agenda de pesquisadores, pondo-se assim em causa um dos produtos mais bem promovidos durante o século XX.

Poder-se-ia pensar que esta nova perspetiva sobre o leite dava afinal razão a orientações alimentares que encontramos noutras propostas com menor aceitação, como a macrobiótica, e que, por esta via, estas propostas se transformavam em propostas mainstream, tal como é sugerido por Lau. ${ }^{1}$ A verdade é que práticas como a macrobiótica raramente são colocadas no centro do debate. É no entanto minha convicção que apesar de nos discursos científicos sobre alimentação ser dada pouca atenção a propostas relativamente marginais, como a macrobiótica, essas propostas acabam por influenciar perspevtivas sobre a alimentação produzidas no âmbito das Ciências da Nutrição.

* Neves Estrela. Leite - bem-me-quer / mal-me-quer. Magna Vita. 2004; no 0, Julho-Agosto: 10-11. 
Noutro lugar, ${ }^{2}$ defendi que a análise da evolução de pirâmides alimentares e a constatação da introdução de alimentos como os que provêm da soja, bem como a diminuição do consumo de produtos lácteos, aproxima as versões mais recentes destas pirâmides das recomendações feitas na macrobiótica, evidenciando uma relação dinâmica entre diferentes conceções sobre alimentação. A "Healthy Eating Pyramid", do Departamento de Nutrição da Harvard School of Public Health, ${ }^{3}$ ao restringir o consumo de leite e de carnes vermelhas e ao incentivar o consumo de proteínas de origem vegetal, como a soja, parece adequar-se à macrobiótica. Esta relação não é, evidentemente, reconhecida, mas podemos colocar a hipótese de as práticas alimentares dos vegetarianos e dos que seguem a macrobiótica terem influenciado a pesquisa científica sobre alimentação.

Os problemas de saúde específicos apresentados por opções vegetarianas, bem como o estado de saúde daqueles que comem de forma diferente, têm suscitado inúmeras pesquisas. Foram essas pesquisas, às quais se juntaram certamente outras, que permitiram à Escola de Harvard definir orientações tão poderosas como o "Prato de Dieta Saudável". ${ }^{3}$ Tendo sido o consumo de produtos derivados da soja amplamente promovido pelas orientações alimentares no âmbito da macrobiótica, observar a restrição na "Healthy Eating Pyramid" do consumo de carne ou leite, ou a introdução de produtos como a soja, parece demonstrar a importância dos movimentos de alimentação saudável no reposicionamento dos consumos aconselhados. ${ }^{2}$

A macrobiótica, bem como outras práticas alimentares que surgem associadas ao que Belasco designa como "contracozinha" (countercuisine), tiveram nas sociedades euro-americanas um valor particular., Não influenciaram apenas a produção, distribuição e consumo de alimentos, aspectos que Goody ${ }^{6}$ enfatizou, mas parecem ter influenciado também as concepções mais institucionalizadas sobre como nos devemos alimentar. Uma relação dinâmica, nem sempre estabelecida e reconhecida, entre diferentes visões (científicas e não científicas) sobre alimentação, deve assim, a meu ver, ser evocada para compreender diferentes orientações alimentares.

O consumo de leite, como já se pôde antever, é alvo de forte controvérsia, sendo pouco recomendado na macrobiótica. Muitas são as razões assinaladas para evitar este alimento, que os chineses, de acordo com Contreras, ${ }^{7}$ classificavam como sangue branco, numa atitude depreciativa. Entre as diferentes justificações referidas na macrobiótica, para que se evite o consumo de leite, contam-se as dificuldades da digestão deste alimento, em particular devido ao processamento da lactose; o fato de conter vestígios de antibióticos e excesso de gordura; de supostamente produzir mucosidades e assim dificultar o trato respiratório; de estar na origem de diversas alergias; de estar associado à diabetes, etc.**

** Contreras refere que 95\% dos aborígenes americanos e 85\% dos árabes apresentam intolerância à lactose. Também em diversas palestras promovidas por divulgadores da macrobiótica, foi referido que a maior parte da população mundial apresentaria tal condição. 
Esse tipo de recomendações, que habitualmente eram associados a regimes alimentares radicais, tem adquirido, no entanto, como referi, uma visibilidade e até um reconhecimento que outrora não existiam. Um dos atos públicos mais notórios de menosprezo pelo leite foram as recomendações contidas na "Healthy Eating Pyramid". De um momento para o outro, aquilo que era a verdade da macrobiótica (o leite como alimento a evitar) é sugerido nos discursos científicos como verdade também para a ciência, criando-se assim um efeito de legitimação de um discurso ao qual faltavam fundamentos científicos. Este efeito não era certamente pretendido pela Harvard School of Health, mas a macrobiótica soube usar essa informação para se procurar legitimar a si própria num processo que pode ser visto como de instrumentalização do conhecimento científico. Perante fatos dessa natureza, é natural que nos questionemos tanto sobre a independência da atividade científica como sobre a suposta falta de fundamentação de propostas como a macrobiótica.

Para Kaptchuk \& Eisenberg, ${ }^{8}$ a convergência que possa existir entre algumas das conceções dos movimentos de "alimentação saudável" e as observações desenvolvidas nas Ciências da Nutrição não deve representar qualquer aproximação entre estas duas formas de abordagem dos alimentos. O fato de as Ciências da Nutrição terem percebido tardiamente a importância dos cereais integrais não significa qualquer aproximação com estes movimentos. O modo como o conhecimento é construído não é similar. Enquanto para os referidos autores as Ciências da Nutrição se baseiam em procedimentos metodológicos característicos da atividade científica, os movimentos de alimentação saudável perseguem uma ideologia e um conjunto de princípios morais e intenções de pureza ética potencialmente perigosos.

Usando como suporte estudos científicos como os de Willet ${ }^{9}$ e Campbell \& Campbell, ${ }^{10}$ alguns dos divulgadores da macrobiótica ultrapassam a fronteira discursiva dos textos fundadores da proposta macrobiótica e usam esses conhecimentos científicos para defenderem que a verdade da macrobiótica tem uma sustentação objetivável. Aparentemente alentados pelo desejo de transformação do mundo, usam a informação disponível, em particular a informação científica que se encontra em consonância com os princípios da macrobiótica, para revelar o que entendem ser a verdade sobre os alimentos - a verdade, nesse sentido, inscrita no saber macrobiótico.

Nesse processo de divulgação, o sentido de missão e de quota-parte de responsabilidade na transformação do mundo é frequentemente reiterado. Para transformar a sociedade, é necessário informar e alterar os indivíduos, e isto só ocorre se estes mudarem seus hábitos alimentares. Assim, o ato de comer, por ser o ato mais íntimo e profundo de incorporação do ambiente, evidencia o corpo como parte indissociável do projeto social que se pretende realizar: um projeto social de maior saúde, paz e harmonia, onde Homem e Natureza se reconciliam.

Se a macrobiótica, enquanto cosmovisão e proposta de orientação no mundo, pode dar voz a este projeto social, não se pense, todavia, que a prática de uma alimentação macrobiótica tem sempre como correlato maior harmonia em termos sociais e familiares. A comensalidade numa 
família onde diferentes elementos têm opções alimentares distintas pode significar, na verdade, transformar a mesa num campo de batalha, não apenas ideológica, mas também física.

No decorrer do trabalho de terreno que desenvolvi sobre práticas alimentares associadas à macrobiótica, tive oportunidade de ouvir relatos que referiam a dificuldade de aceitação de novos hábitos alimentares e que evidenciavam resistência à exclusão de alimentos que eram consumidos habitualmente, como a carne ou o leite. Se a ideia de convivialidade, frequentemente associada à comensalidade, constitui um tópico a explorar e analisar, pelo sentido e valor que confere à vida social, também a conflitualidade à mesa pode ser o resultado dessa mesma comensalidade, desde que associada à imposição de uma dieta rígida e a uma visão específica sobre os alimentos. Perspectivar a comida como campo de combate ideológico, tal como foi sugerido por Mintz, ${ }^{11}$ surge como recurso prestimoso numa análise da comensalidade. A macrobiótica, na sua afinidade com muitos dos termos New Age, que remetem a uma concepção holística e espiritualizada do universo, apresenta uma forma de ver o mundo que, pelo conjunto de princípios, valores e significados que gera, pode ser identificada com ideologia.

A passagem com que iniciei esta comunicação é esclarecedora quanto a certo tom que, de forma reiterada, encontrei quando frequentei cursos e palestras dedicadas a esse tipo de alimentação, ou quando falei com pessoas que praticavam alimentação macrobiótica. Verifica-se, na verdade, forte insistência na ideia de que necessitamos de educação alimentar, que somos mal informados acerca dos alimentos que consumimos, que se foram criando mitos sobre a alimentação que devem ser desmontados e que há trabalhos que demonstram que muitos dos discursos dominantes sobre a alimentação servem sobretudo à indústria alimentar. Aquilo que nessas formações se propõe, a partir destas constatações, é um novo posicionamento, mais crítico, face às verdades instituídas; uma narrativa capaz de conduzir àquilo que chamam o "despertar da consciência”, para usar uma expressão êmica. Desta forma, os defensores desta corrente salientam a ideia de que é necessário um intenso trabalho de divulgação para que possam ser desfeitas algumas das falácias sobre as quais se foi construindo o saber alimentar.

\section{Macrobiótica: uma proposta new age?}

É precisamente na evocação desse projeto social que a macrobiótica procura veicular que gostaria de me deter, pois vários aspectos da proposta macrobiótica remetem para esse vasto universo de sentidos que é o New Age e sugerem a inscrição da macrobiótica nesse campo, ainda que muitos de seus partidários não se reconheçam nele. Na verdade, pude recolher depoimentos em que se frisava que a macrobiótica não era "um pacote New Age" ou "que nada tinha a ver com essa espiritualidade de supermercado". Outros desconheciam mesmo o que o termo "New Age" pudesse significar. Esta ignorância ou demarcação face à New Age não obsta, porém, que possam ser 
assinalados diversos pontos de contato entre a macrobiótica e este movimento. Procurarei assinalar, ainda que de forma muito resumida, algumas das características comuns entre a macrobiótica e a New Age, para evidenciar conexões da macrobiótica com seu espírito.

Os dados etnográficos em que me apoio são relativos à pesquisa sobre a macrobiótica desenvolvida em Portugal entre 2001 e 2009, no âmbito de um projeto de doutoramento que visava analisar as práticas e representações associadas à macrobiótica em Portugal. ${ }^{4}$ A pesquisa foi sobretudo desenvolvida em duas cidades portuguesas, Braga e Lisboa, escolhidas porque se justificava observar de que forma circulavam pessoas, informações, significados, produtos e práticas entre diferentes lugares: um que apresentava maior centralidade (Lisboa) e outro que tinha um caráter mais periférico (Braga).

Combinando o registro de observações com longas conversas informais, entrevistas e participação em diversos eventos relacionados com a macrobiótica, contactei cerca de uma centena de indivíduos que com ela tinham afinidades. Desenvolvi, assim, uma análise qualitativa e intensiva, característica da abordagem etnográfica, e adotei um posicionamento mais compreensivo do que explicativo. Procurando uma informação tão densa quanto possível, frequentei durante cerca de dez anos lugares de encontro e formação associados à macrobiótica. Meus contextos de observação se tornaram bastante diversificados. Palestras, cursos de cozinha, o curso curricular Michio Kushi no Instituto Macrobiótico de Portugal (IMP), um curso de shiatsu em Braga (prática com afinidades com a macrobiótica), as observações no consultório de orientação alimentar macrobiótica, a participação em residenciais de formação, nos campos de férias organizados no âmbito de atividades ligadas à macrobiótica, a frequência de restaurantes e estabelecimentos comerciais constituíram muitos dos lugares onde desenvolvi esta pesquisa.

Inspirada em filosofias orientais, como o taoismo e o budismo zen, a macrobiótica orienta-se por uma lógica dualista de classificação dos alimentos que os separa entre yin e yang. ${ }^{12}$ Embora sejam admitidas diferentes gradações de yin e de yang, esta é efetivamente a matriz simbólica a partir da qual os alimentos devem ser pensados e selecionados. De uma ingestão ponderada de alimentos pertencentes a essas categorias resultaria um corpo mais saudável. Uma "condição equilibrada" seria visível na qualidade do sangue, que não deveria ser nem excessivamente ácido, nem excessivamente alcalino, devendo ter uma proporção adequada entre níveis de sódio e potássio. Assim, alimentos que nesta conceção sobre alimentação são classificados como detendo valores elevados de potássio, como as batatas ou as bananas, são vistos como nocivos e potencialmente perturbadores. Uma alimentação harmoniosa deveria basear-se na ingestão de cereais integrais e vegetais de boa qualidade.

Mais do que preocupar-se exclusivamente com o corpo e com os alimentos, a macrobiótica apresenta-se como vasto programa cujo escopo é a regeneração da humanidade e a reconciliação entre Homem e Natureza. Este objetivo é perseguido, certamente, através de intenso trabalho sobre o corpo, com uma seleção criteriosa dos alimentos que mais lhe convêm. Alicerça-se nesse corpo 
para uma finalidade de grande alcance: o desenvolvimento da compreensão da "ordem natural do universo". O projeto social de uma humanidade regenerada é, assim, procurado através de um projeto individual que se concentra no corpo e nos alimentos que o constroem.

Na macrobiótica, tal como nos discursos ligados à New Age, encontramos a ideia de que o modo de vida moderno, dominado por uma ciência de matriz tecnológica e materialista, está colocando em perigo a saúde humana e o planeta. Apontado como causa de stress, sofrimento e frustração, este modo de vida é então encarado como desorientação que urge contrariar. O Homem necessita, como dizem alguns dos formadores que contactei, ser redirecionado, "evoluir tanto no plano biológico como espiritual", e para isso precisa conhecer as leis do universo.

Na tentativa de encontrar uma sintonia com o mundo, o conceito de "energia" é evocado como tópico fundamental na explicação de qualquer realidade - tudo é manifestação de energia - e o universo deve ser visto como um todo uno, numa perspectiva monista, percebido através de um paradigma holístico, onde se reconheça a interdependência de todos os fenômenos; onde cada parte represente um microcosmos do universo. Procura-se desenvolver, assim, uma consciência planetária, que conduza ao reconhecimento de que todos os atos se encontram inter-relacionados e que, pela ação individual é possível contribuir para a transformação do planeta.

Nesta lógica, o tema da responsabilidade individual assume importância maior: o desejo de transformação do mundo começa a concretizar-se na transformação do próprio indivíduo, através do trabalho interior que o conduza a uma modificação pessoal e, concomitantemente, à transformação do planeta. É transformando a sua própria consciência e modo de ação que o sujeito conseguirá modificar, indiretamente, a sociedade. Para levar a cabo a mudança que afirmam ser necessária, o indivíduo não necessita de se apoiar em estruturas religiosas organizadas; o non credo é, de resto, um dos princípios defendidos na macrobiótica: as diferentes religiões são apenas diferentes caminhos na descoberta da espiritualidade, tal como os raios de uma roda que convergem para o seu centro. O Homem deve ter sobretudo uma "fé incondicional na ordem da natureza", saber ouvi-la, "desenvolver a sua intuição, a sua percepção do subtil" e "ser o seu próprio mestre".

Como vemos, vários aspectos sugerem a inscrição da macrobiótica na New Age. Desde logo, a inspiração oriental e certo sincretismo em termos filosóficos, mas imediatamente, o monismo, ou seja, a crença num princípio único do qual tudo deriva, a concepção do universo como um todo uno, o paradigma holístico, a valorização do conceito de energia, a preocupação com a espiritualidade, a valorização da intuição e a focalização no indivíduo que permitem a autores como Heelas, ${ }^{13}$ Lacroix, ${ }^{14}$ ou Vernette ${ }^{15}$ referir a sacralização do eu.

O fenômeno New Age apresenta-se como um novo paradigma que procura entender o mundo partindo da ideia de conexão e interdependência entre todos os fenômenos. Faz crença na existência de um espírito universal que coloca em comunhão homens e coisas. As perspetivas New Age contestam frequentemente a modernidade e os ídolos que esta criou, a "ditadura» da razão, 
da ciência e da técnica. Acreditam no advento próximo de um mundo renovado que pode ser agitado e problemático, mas que será sempre uma nova era, em que cada homem se reconhecerá como fragmento da consciência cósmica. ${ }^{16}$

Para além dessas especificidades, a New Age tem ainda como características não se encontrar baseada num dogma, num texto, numa organização central, ou numa referência geográfica particular. Procura antes afirmar-se como um movimento espiritual livre, sem relação com uma religião organizada de modo formal. É um movimento heterogêneo, "uma nebulosa", como lhe chama Vernette, que tem como fontes a astrologia, o hinduísmo, o taoismo, as tradições gnósticas, o espiritismo, o ocultismo, a teosofia, as tradições neo-pagãs, etc."** Uns servem-se da astrologia, outros das cartas do tarô, outros da energia dos cristais, outros do channeling, outros da fonte curativa da energia cósmica ou do potencial humano e por aí adiante...

Em fenômenos tão heteróclito que facilmente misturam novas abordagens com sistemas tradicionais ou recriação destes, esta heterogeneidade não constitui, todavia, um problema, já que, como referi, cada um pode escolher a via que mais lhe convenha. Na New Age a divulgação dos diferentes caminhos para a realização espiritual, não se faz através de serviços religiosos ou de sermões, mas através de seminários, cursos, publicações, workshops, retiros, etc..

Vejamos, pois, qual o perfil sociográfico dos que frequentam cursos e workshops na área da macrobiótica. Para a obtenção deste perfil, recorri ao arquivo do Instituto Macrobiótico de Portugal, onde se encontram os registros relativos às fichas de inscrição dos alunos do IMP. Nas fichas figuravam questões relativas à idade, à formação e à profissão, bem como questões sobre o interesse pela área da macrobiótica, referência a doenças que os afetavam, utilização de medicamentos, etc. Foi-me assim possível aceder a um conjunto sistematizado de dados sobre o conjunto de indivíduos que frequentaram os cursos do IMP (Curso de Culinária Macrobiótica e Curso Curricular Michio Kushi) em três anos letivos consecutivos: 2005-06; 2006-07 e 2007-08. Foram analisados 181 registros: 144 mulheres e 37 homens, com idades entre os 17 e os 61 ou mais anos. A faixa etária mais frequentada correspondia à classe de idades entre os 31-35 anos de idade (40 de 176 alunos), encontrando-se os restantes distribuídos da seguinte forma:

Quadro 1 - Distribuição segundo a idade dos participantes

\begin{tabular}{|c|c|c|c|c|c|c|c|c|c|}
\hline Idades & $\mathbf{1 7 - 2 5}$ & $\mathbf{2 6 - 3 0}$ & $\mathbf{3 1 - 3 5}$ & $\mathbf{3 6 - 4 0}$ & $\mathbf{4 1 - 4 5}$ & $\mathbf{4 6 - 5 0}$ & $\mathbf{5 1 - 6 0}$ & $\mathbf{2} \mathbf{6 1}$ & Total \\
\hline & 28 & 30 & 40 & 22 & 25 & $\mathbf{1 4}$ & $\mathbf{1 0}$ & $\mathbf{7}$ & $\mathbf{1 7 6}$ \\
& $16 \%$ & $17 \%$ & $23 \%$ & $13 \%$ & $14 \%$ & $\mathbf{8 \%}$ & $\mathbf{6 \%}$ & $\mathbf{4 \%}$ & \\
\hline
\end{tabular}

*** O New Age enquanto movimento organizado, reivindicativo e atuante junto de instâncias de decisão, parece ter pouca expressão na Europa. O que não quer dizer, evidentemente, que haja uma invisibilidade dos "produtos" New Age. Ao contrário, estes, em boa verdade, estão em franca expansão. Por outro lado, muito embora pareça útil falar de movimento, tal não significa que haja uma estrutura organizada. 
É possível constatar que foram sobretudo as mulheres que frequentaram esses cursos. Em 171 registros considerados válidos para averiguar o nível de escolaridade dos participantes, verificouse que 99 tinham formação de nível superior e que 72 tinham formação ao nível do 3o ciclo do ensino básico e do secundário. Verificamos, portanto, que os níveis de escolaridade são neste grupo bastante elevados.

Entre as profissões referidas (foram consideradas 138 respostas válidas), a categoria mais frequentada foi a de especialistas das atividades intelectuais e científicas, 64 indivíduos afirmavam exercer profissões nesta área. Arquitetos, professores, atores, bailarinos, investigadores, jornalistas e cineastas foram alguns dos profissionais que foram integrados nesta categoria. ${ }^{16}$ Como é fácil verificar, o conjunto de pessoas que frequenta estes cursos possui um elevado grau de instrução e pertence às classes média/média-alta. Como vemos, a "simpatia" por este tipo de propostas, por vezes referidas como menos racionalizadas, está longe de recair sobre uma população com fraca formação escolar.

Característico da New Age é também o movimento de saúde holística que presta atenção ao Homem como um todo - mente, corpo e espírito - e que procura não se centrar apenas na dimensão física da doença, mas reconhecer seus aspectos psicológicos, sociais e espirituais. Como refere Vernette, a saúde holística "em vez de intervir principalmente pela química e pelos medicamentos, procura a intervenção mínima por uma tecnologia apropriada, a partir de uma panóplia de técnicas não invasoras: psicoterapias, exercícios físicos, regimes alimentares”.**** Sistemas de cura, como a acupunctura, a reflexologia, a iridologia, o uso de cristais, o shiatsu, o reiki, a homeopatia e a macrobiótica, como veremos, encontram aqui lugar de acolhimento. Nestas propostas terapêuticas, é suposto agir-se não apenas sobre o corpo físico, mas sobretudo naquilo que é visto como sistemas e canais de energia do corpo etéreo (corpo subtil), de forma a repor aquilo a que chamam equilíbrio energético. Age-se sobre os meridianos e sobre os chakras; harmonizam-se o yin e o yang.

\section{Movimentos de saúde holística}

A macrobiótica, enquanto proposta terapêutica, ao procurar harmonizar a energia yin e yang, encontra claramente, pelo que já fui dizendo, espaço de referência no movimento New Age de saúde holística. A mudança de hábitos alimentares que propõe desencadeia frequentemente, tal como é notado por Ossipow, ${ }^{17}$ uma redefinição dos projetos individuais e familiares e alteração no modo de vida. A macrobiótica dirige-se não apenas ao sujeito físico, mas também mental, espiritual e social. O indivíduo é visto como locus de autoridade e como responsável por sua saúde ou doença.

**** Vernette J. New Age. Mem Martins: Publicações Europa-América. s/d : 64. 
Defende-se, na macrobiótica, que somos efetivamente o que comemos e que as doenças podem ser evitadas e combatidas à mesa. Uma alimentação inadequada não permite uma plena realização humana, e atrapalha, como dizem, "a capacidade de discernimento" e "evolução espiritual”. Os praticantes desse tipo de alimentação submetem-se, assim, a uma higiene corporal que passa pela ingestão de alimentos purificadores, capazes de melhorar a "qualidade do seu sangue" e de toda sua "estrutura celular". Devem evitar, por outro lado, alimentos tidos por tóxicos, conspurcadores, poluidores, como a carne, que "enfraquecem o sangue" e, simultaneamente, o sistema imunitário e a estrutura geral da pessoa.

As críticas relativamente ao movimento New Age de saúde holística são frequentes e, por este motivo, muitos seguidores da macrobiótica não gostam de se rever nele. Hans Baer ${ }^{18}$ salienta, por exemplo, que nos Estados Unidos o desencantamento de alguns dos gurus da New Age face à biomedicina em vez de originar um movimento de luta por alteração nas políticas de saúde, acabou por, ao centrar-se no indivíduo e nos seus estilos de vida, levar a uma demissão do ponto de vista social. Adotando uma atitude moralista face à saúde, as propostas de saúde holística acabaram por se dirigir sobretudo aos mais ricos, àqueles que podiam pagar serviços de saúde não comparticipados. Constatou Baer, por outro lado, que muitos dos new agers que pregavam contra o materialismo, como Andrew Weil e Deepak Chopra (divulgadores referidos por Baer), exibiam riqueza de forma ostensiva, contrariando assim a ideia, por vezes defendida, de que a New Age pode ajudar a transformar as estruturas capitalistas. É nesse mesmo sentido que se expressa Lau, ${ }^{1}$ ao integrar a macrobiótica no espírito do capitalismo. As práticas New Age de saúde holística são vistas por Baer como reforçando essas estruturas, sendo que o apelo a um atendimento mais personalizado nos cuidados de saúde e a excessiva individualização desses mesmos cuidados se encontra em perfeita consonância com a estrutura capitalista. Para além disso, a biomedicalização da própria saúde holística seria mais um sinal de conformidade com o sistema capitalista.

Apesar desses argumentos, muitos deles aparentemente válidos, Baer subestima, efectivamente, alguns dos efeitos produzidos pelas abordagens holísticas do corpo. Lançando um verdadeiro ataque a dois de seus representantes e divulgadores (Andrew Weil e Deepak Chopra), enquadra o marketing New Age no sistema capitalista e ignora os que procuram este tipo de cuidados e o grau de satisfação que possam ter com eles. Menosprezando a importância das transformações pessoais, atribui, assim, pouco valor ao sentido de responsabilidade individual, optando por eclipsar o indivíduo, neste caso, o paciente, da sua análise.

Voltando à macrobiótica, importa sublinhar que, na verdade, vários elementos apontam para a inscrição dessa prática no movimento New Age de saúde holística. Dos dados etnográficos recolhidos, constato que muitas pessoas resolvem problemas de saúde com este regime alimentar. Verifico também que recorrem pouco ao serviço nacional de saúde e que desconfiam frequentemente dos serviços prestados, não excluindo, porém, a possibilidade de os utilizar. Consideram que os tratamentos são aí mais agressivos e que, por isso, não devem constituir a primeira opção. Defendem 
que sempre que for possível e adequado, se deve recorrer primeiro a terapias menos invasivas. Constato, desta forma, que para muitos a macrobiótica é eficaz e conduz à redefinição de projetos de vida, não devendo, nesta medida, ser inteiramente rejeitada enquanto proposta de saúde holística, pois correr-se-ia o risco de “deitar fora o bebê com a água do banho”. O exercício crítico e de ridicularização dessas propostas são admissíveis, pois parece haver, segundo dizem, muito joio que se mistura com o trigo, é também certo que elas se inscrevem numa certa modernidade, numa certa estrutura capitalista, mas isto não lhes retira em diversos casos eficácia.

\section{Macrobiótica e new age: convergências}

Procurei com este texto estabelecer conexões entre a macrobiótica e o "movimento" New Age, fazendo referência a diversos tópicos que podem ser reencontrados nessas propostas. Comecei por fazer referência a questões ligadas à alimentação e à convergência em certos aspectos relacionados com escolhas alimentares feitas na macrobiótica e nas Ciências da Nutrição. A referência a esta convergência permitiu-me não apenas observar algum dinamismo entre essas áreas como destacar os processos de racionalização e de instrumentalização do conhecimento científico que ocorrem na macrobiótica.

Este dado é relevante na medida em que nos permite detectar procedimentos através dos quais certas áreas, no caso a macrobiótica, procuram adquirir autoridade e legitimidade. O que verificamos é que propostas que contestam a modernidade e a compreensão muito racionalizada da realidade acabam por fazer uso seletivo da ciência para se afirmarem. Este procedimento, mais do que estratégia específica da macrobiótica, caracteriza a "nebulosa» New Age e evidencia suas próprias racionalidades.

Nessa medida, a referência que é feita neste texto a aspectos convergentes entre macrobiótica e Ciências da Nutrição julgo ser útil para compreender processos de construção discursiva que darão visibilidade a muitos dos tópicos que habitualmente identificam a New Age. Por fim, fiz referência aos efeitos que a adesão à macrobiótica e outras tendências New Age podem causar. Estas propostas, conhecidas pela sua contestação ao sistema, integram-se perfeitamente no sistema económico-social vigente, podem não ser mainstream, mas atuam nele de forma muito agencializada, liberal, focada na responsabilidade individual e esquecida da responsabilidade coletiva.

\section{Referências}

1. Lau K. New age capitalism, making money east of eden. Philadelphia: University of Pennsylvania Press; 2000.

2. Calado, V. “À Mesa com o Universo”, a proposta macrobiótica de experiência do mundo [dissertação]. Lisboa: Instituto de Ciências Sociais da Universidade de Lisboa; 2012. 
3. Harvard School of Public Health. Food pyramids and plates: what should you really eat? [Internet] 2015. Disponível em: http://www.hsph.harvard.edu/nutritionsource/what-should-you-eat/pyramidfull-story/index.html

4. Belasco W. Food and the counterculture: a story of bread and politics. In. Watson J, Caldwell M, editores. The cultural politics of food and eating, a reader. Oxford: Blackwell Publishing; 2005. p. 217-234.

5. Belasco W. Appetite for change, how the counterculture took on the food Industry. Ithaca e London: Cornell University Press; 2007.

6. Goody J. Cozinha, culinária e classes. Oeiras: Celta; 1998.

7. Contreras J. Antropología de la alimentacion. Salamanca: Eudema; 1993.

8. Kaptchuk T, Eisenberg D. The health food movement. Nutrition 1998; 14:5:471-73.

9. Willett W, Skernett P. Eat, drink and be healthy: the Harvard Medical School Guide to healthy eating. New York: Free Press; 2005.

10. Campbell C, Campbell T. The China study: the most comprehensive Study of nutrition ever conducted and the starling implications for diet, weight loss and long-term health. Dallas: Benbella Books; 2005.

11. Mintz S. La comida como un campo de combate ideolóxico. In Conferencia de Clausura del VIII Congreso de Antropología. Homenage a la Xeración Nós. Santiago de Compostela: Federación de Asociaciones de Antropología del Estado Español; 1999. p. 1-17.

12. Kushi M, Jack A. The book of macrobiotics, the universal way of health, happiness, and peace. Tokio: Japan Publications; 1989.

13. Heelas P. The new age movement, the celebration of the self and the sacralization of modernity. Oxford: Blackwell Publishers; 1999.

14. Lacroix M. A ideologia do New Age. Lisboa: Instituto Piaget; 2000.

15. Vernette J. New Age. Mem Martins: Publicações Europa-América; 1992.

16. Portugal. Instituto Nacional de Estatística. Classificação Portuguesa das Profissões 2010. Lisboa: INE; 2010.

17. Ossipow L. La cuisine du corps et de l'âme, approche ethnologique du végétarisme, du crudivorisme et de la macrobiotique en Suisse. Neuchâtel: Editora l'Institut d'Ethnologie; 1997.

18. Baer HA. The work of Andrew Weil and Deepak Chopra: the two holistic health/new age gurus: a critique of the holistic health: new age movements. Medical Anthropology Quarterly 2003; 17(2):233-250.

Recebido: 15/4/2015

Revisado: 02/6/2015

Aprovado: 27/6/2015 